\title{
Optimal Selection and Location of Tower Crane for the Construction of Prefabricated Buildings with Different Prefabrication Ratios
}

\author{
Chunlei Huang ${ }^{1}$, Rongyan $\mathrm{Li}^{2}$, Yan $\mathrm{Fu}^{2^{*}}$ and Vernon Ireland ${ }^{3}$ \\ ${ }^{1}$ Faculty of transportation and municipal engineering, Chongqing Jianzhu College, Chongqing 400072, China \\ ${ }^{2}$ School of Management Science and Real Estate, Chongqing University, Chongqing 400045, China \\ ${ }^{3}$ Faculty of Engineering, Computer and Mathematical Sciences, The University of Adelaide, Adelaide, South Australia 5005, Australia
}

Received 3 October 2019; Accepted 17 December 2019

\begin{abstract}
Tower cranes had been used extensively with the new upsurge of prefabricated buildings in China. Construction time and cost could be affected by the prefabrication ratio of prefabricated buildings, the selection and location of tower cranes. This study proposed a cost-based selection and location optimization model for tower crane to reveal the relationship between the prefabrication ratio and the optimal selection and location of tower crane. Moreover, this study further discussed different prefabrication ratios. The range of the tower crane type was preliminarily determined on the basis of its performance parameters and the construction project scope. The location scope of the tower crane was determined by investigating the positional relationship among tower crane and supply and demand points. Then, the optimal selection and location of the tower crane were obtained with the lowest cost. Three typical construction cases were discussed under different prefabrication ratios by taking a ten-story prefabricated building in Chongqing as an example. Results demonstrate that when the required prefabrication ratio is not less than $30 \%$, selecting prefabricated beam is the most economical for the construction project. When the number reaches $50 \%$, the combination of prefabricated columns and beams is the most economical. The lowest cost of the tower crane is obtained when the supply point is located at the midpoint of the long side in the construction project. The proposed method provides reference for the selection of prefabricated components and the selection and location of tower crane of prefabricated buildings.
\end{abstract}

Keywords: Tower crane, Prefabricated building, Prefabrication ratio, Selection of tower crane, Location of tower crane

\section{Introduction}

Construction layout is an integral part of on-site construction management. A reasonable on-site layout can increase productivity and reduce construction costs. Equipment costs account for a high proportion of the total construction cost of high-rise buildings [1]. Therefore, optimizing equipment layout, such as tower cranes, can accelerate construction schedule and reduce construction costs. Tower crane is an important construction equipment because of its high cost. Moreover, tower cranes play a key role in the vertical and horizontal transport of prefabricated components [2]. The operational efficiency of tower cranes determines the schedule of construction projects. In recent years, building industrialization has entered a comprehensive development period in China. The promotion of prefabricated buildings is an important stage in the industrialization process [3]. The use ratio of tower cranes has been substantially improved, compared with the traditional cast-in-place construction. However, in the existing layout of prefabricated building construction, the selection and location of tower cranes still lack pertinence. Managers are still learning from their traditional construction experience. The prefabrication ratio is an important factor required by the government to contractors [4]. The combination of different prefabricated components corresponds to various prefabrication ratios. Different types of prefabricated components vary in terms of installation positions and lifting times, which have diverse effects on the selection and location of tower cranes. However, the influence mechanism of prefabrication ratio on the selection and location of tower crane is unclear.

Scholars have conducted numerous studies on the influencing factors and mathematical models of the location of tower cranes [5-8]. However, studies on the selection process of the tower crane model and the influencing mechanism of external factors are limited. Therefore, exploring the factors that influence the selection of tower cranes and clarifying the effect of prefabrication ratios on the selection and location of tower cranes is necessary.

The mathematical model of the optimal selection and location of tower cranes is constructed on the basis of the aforementioned analysis, considering the factors that influence the selection and location of tower cranes, combined with the optimization goal of minimizing cost. Moreover, the influence mode and effect of prefabrication ratios are analyzed to discuss the optimal prefabricated component combination and the optimal selection and location of tower cranes. Case studies are carried out to provide a reference for the combination of prefabricated components and the selection and location of tower crane under different prefabrication ratios. 


\section{State of the art}

At present, scholars have carried out various studies on the location of tower cranes. Existing studies mainly focus on three aspects, namely, mathematical models, optimization algorithms, and simulation techniques. After nearly 30 years of study, the mathematical model has gradually become specific. The present study began with the optimal location of a single tower crane. Richard L. Francis and Walter Zhang [8] described the positive correlation between the lifting radius and capacity of tower cranes to minimize transportation costs. They proposed the arrangement range of tower crane based on the known demand and supply points and established a mathematical model based on the lifting process. However, they failed to consider the coordinated movement in the lifting process. With economic development, many large projects require multiple tower cranes to work together to meet the tight schedule requirements. Therefore, Zhang [9] proposed a location model for multiple tower cranes to minimize collision of tower cranes and the reasonable task allocation. The static model did not involve dynamic construction process. C. Huang [10] introduced a mixed-integer linear programming method, which was only applied to the calculation of smallscale construction projects, to realize the optimal location of tower cranes. In addition, they added the formula for calculating the vertical transportation time and parameter $\alpha$ to improve the model, and $\alpha$ showed the degree of synchronization between the jib rotation and the trolley sliding movement. Considering the costs of installation, disassembly, maintenance, and operation of tower cranes, $\mathrm{Li}$ Chuanlian [11] improved the cost structure of tower cranes but ignored the main cost composition, the foundation of tower crane. Yeoh [12] constructed a phased tower crane dynamic selection and location model but failed to provide a standard for the division of construction stages, and the application scope was small because the model was based on BIM. Zhu Fang [13] stated that the requirements of the tower crane foundation for geology and surrounding environment were non-negligible. However, the qualitative law was proposed on the basis of actual experience and lacked the judgment standard. Marzouk [7] used AHP to explore the main factors that influenced the selection of tower crane types but neglected the selection of specific crane models. Song Yigong [14] proposed that the building's height was an important factor that influenced the selection of tower cranes based on the characteristics of fabricated buildings and practical experience. However, he did not analyze the influencing mechanism and effect quantitatively.

The previous study mostly used the mathematical optimization algorithm to reduce calculation time and realize the optimal location of tower cranes and examined the feasibility of the results through simulation to ensure hoisting safety. When determining the optimal location of the tower crane, Tom [15] used genetic algorithm and artificial neural network to accelerate the calculation. However, the mathematical model for tower crane lifting was not perfected. Kaveh, A [16] comprehensively compared five optimization algorithms, namely particle swarm optimization, colliding bodies optimization, enhanced colliding bodies optimization, vibrating particles system, and enhanced vibrating particles system, to obtain the optimal location of the tower crane and the storage location. The results enriched the application choice of the optimization algorithm and improved calculation accuracy. However, there still are a certain gap between the exact solution and the output of above optimization. Scholars used various simulation and visualization techniques to understand the results of algorithms and validation models. Irizarry [17] used building information modeling (BIM) and geographic information system (GIS) to communicate and integrate information, which was limited to construction projects with BIM models. Xiang Hui [18] used BIM space collisionprevention technology for the selection and location of tower cranes to avoid the collision with high-voltage lines. However, he neglected the tower crane operating efficiency. Pan Weikang [19] used 5D technology to realize the dynamic simulation of multitower crane construction scheme to intuitively observe and analyze the construction process of tower crane group. In addition, he analyzed the coordination of BIM technology in the operation and control of multiple tower cranes, which was only suitable for program comparison and selection.

The results of the above analysis mainly focus on the application of mathematical models, optimization algorithms, and simulation technology of the location of tower crane. However, the research on model selection of tower crane, specifically the quantitative research on external influencing factors, is limited. Different prefabrication ratios mean dissimilar combinations of prefabricated components. And different prefabricated components are installed at various locations, which significantly influence the selection and location of tower cranes. Therefore, the present study established a tower crane location scope model based on the location relationship among tower crane, demand point, and supply point. Furthermore, the present study proposed the tower crane location optimization model and algorithm combined with the lifting process and the cost optimization goal. The influence mode and effect of prefabrication ratios on the optimal selection and location of tower cranes were expected to determine the optimal combination of prefabricated components on the premise of meeting the requirements for prefabrication ratios. Combined with the case analysis, the results provide guidance for the selection and location of tower cranes.

The remainder of the present study is organized as follows. Section 3 describes the specific components of the tower crane selection and location optimization model: tower crane primary selection model, tower crane location scope calculation model, tower crane cost calculation model, and tower crane lifting time calculation model. Section 4 calculates the corresponding prefabrication ratio, the optimal cost, and the optimal selection and location of tower cranes by taking a ten-story prefabricated building in Chongqing as an example. Moreover, Section 4 obtains the optimal combination of prefabricated parts and the optimal selection and location of tower crane under different prefabrication ratios. Finally, Section 5 draws relevant conclusions.

\section{Methodology}

\subsection{Tower crane primary selection model}

Lifting capacity of tower crane is a key factor that influences the selection of the tower crane model, which is expressed as the load moment $M$. The load moment refers to the product of the radius $L$ and the corresponding load $Q$, and the unit is $\mathrm{kN} \cdot \mathrm{m}$ or $\mathrm{t} \cdot \mathrm{m}$. Radius $L$ corresponds to the horizontal distance from the rotation centerline of the rotation platform to the vertical centerline of the load handling device when the crane is placed in a horizontal field. The maximum radius of a tower crane is $L_{\text {max }}$, and the corresponding load 
capacity is $Q_{L \max }$. Fig. 1 shows the relationship of radius $L$ and load $Q$.

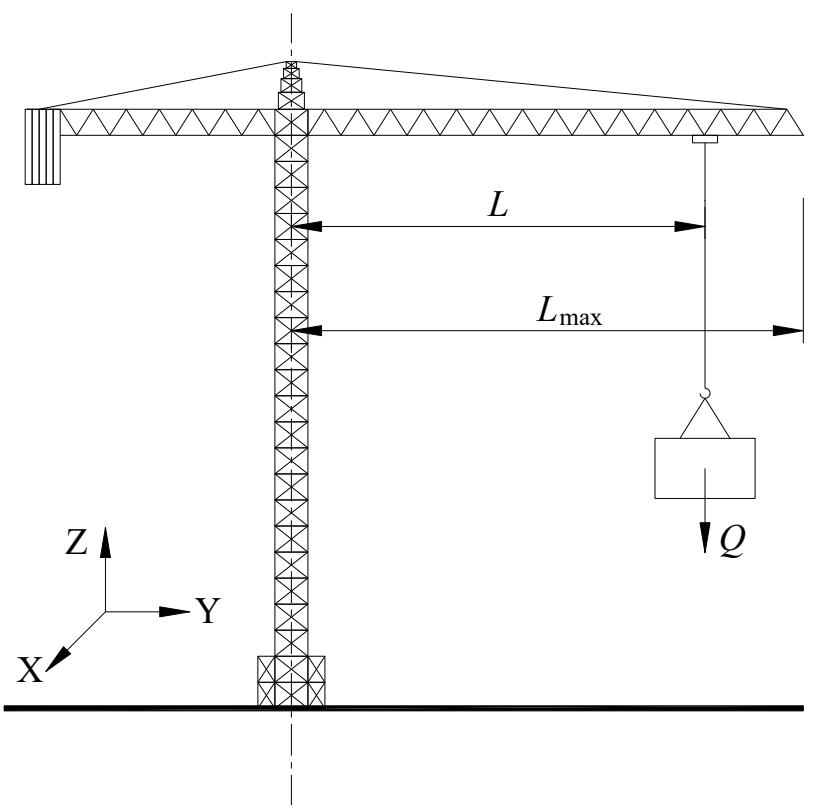

Fig. 1. Schematic of radius $L$ and load $Q$

The necessary conditions for the tower crane to successfully lift and install heavy loads are as presented as:

The tower crane is located at FP (expressed by central point of tower crane location), and its radius $L_{\max }$ should cover the supply point SP (expressed by central point of supply area location) and the demand point DP (expressed by central point of installation position of prefabricated components), as shown in Eq. (1) (Fig. 2);

$$
\max \left(L_{\mathrm{FS}}, L_{\mathrm{FD}}\right) \leq L_{\max }
$$

where $L_{\mathrm{FS}}$ is the horizontal distance from FP to SP, and the unit is $\mathrm{m} ; L_{\mathrm{FD}}$ is the horizontal distance from FP to DP, and the unit is $\mathrm{m} ; L_{\max }$ is the maximum radius, and the unit is $\mathrm{m}$.

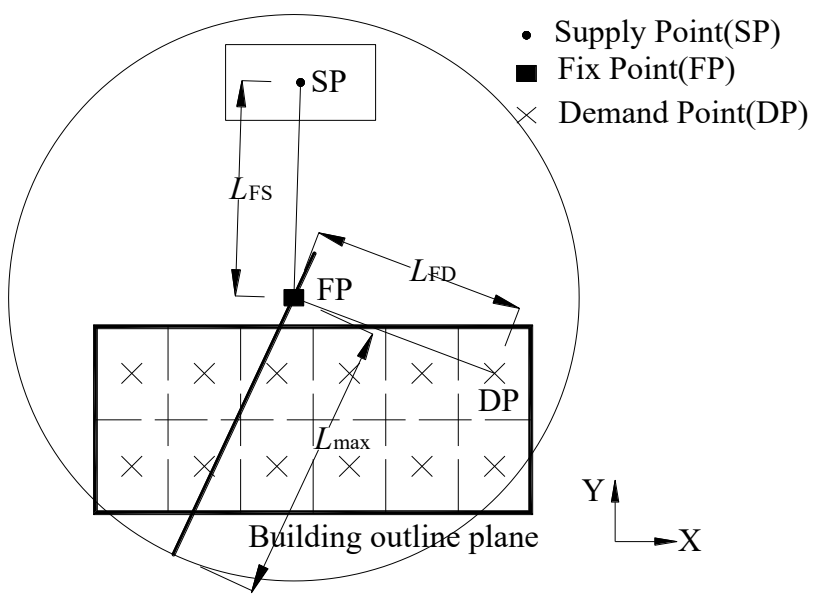

Fig. 2. Plane graph of tower crane

The variation curve of the load capacity of the same tower crane presents the segmented nature (Fig. 3). Taking C5013 as an example, "C" represents "crane," 50 denotes the maximum radius $L \max$ of tower crane, and the unit is $\mathrm{m}$.
The number 13 indicates the load capacity $Q_{L \max }$ that corresponds to the maximum radius $L_{\max }$ which is 1.3 tons, and the unit is ton $(\mathrm{t})$. When radius $L$ is not less than $3 \mathrm{~m}$ and not more than $12.3 \mathrm{~m}$, the load capacity is always $8.0 \mathrm{t}$. When radius $L$ is greater than $12.3 \mathrm{~m}$, the load capacity decreases with the increase of radius $L$.

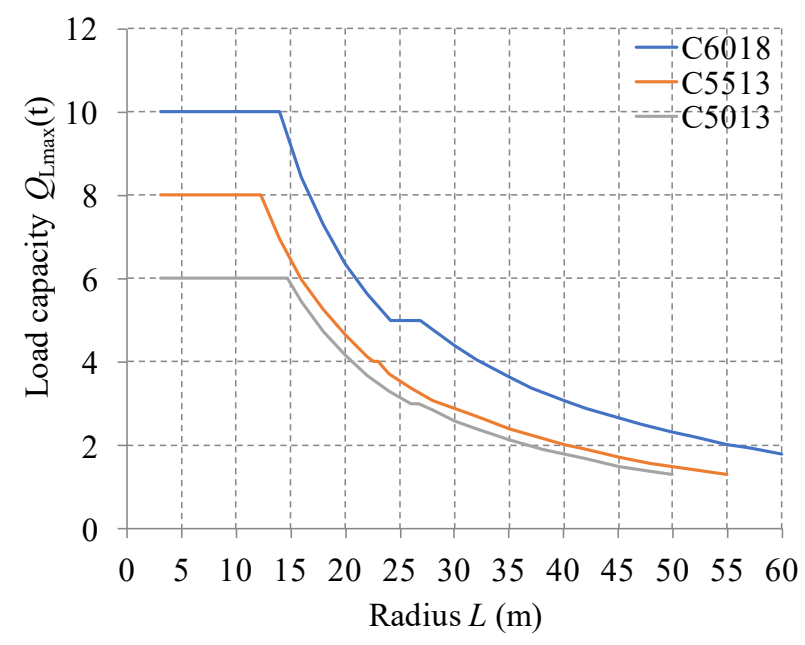

Fig. 3. Diagram of the relationship between radius and load capacity

\subsection{Tower crane location scope calculation model}

The location scope of tower cranes mainly depends on the mass and the installation location of the prefabricated components and the load moment of the tower crane. In general, the mass and the installation location of prefabricated components are determined during the design phase. Three installation points of prefabricated components (e.g., $\mathrm{DP}_{1}, \mathrm{DP}_{2}$, and $\mathrm{DP}_{3}$ ) are selected in Fig. 4.

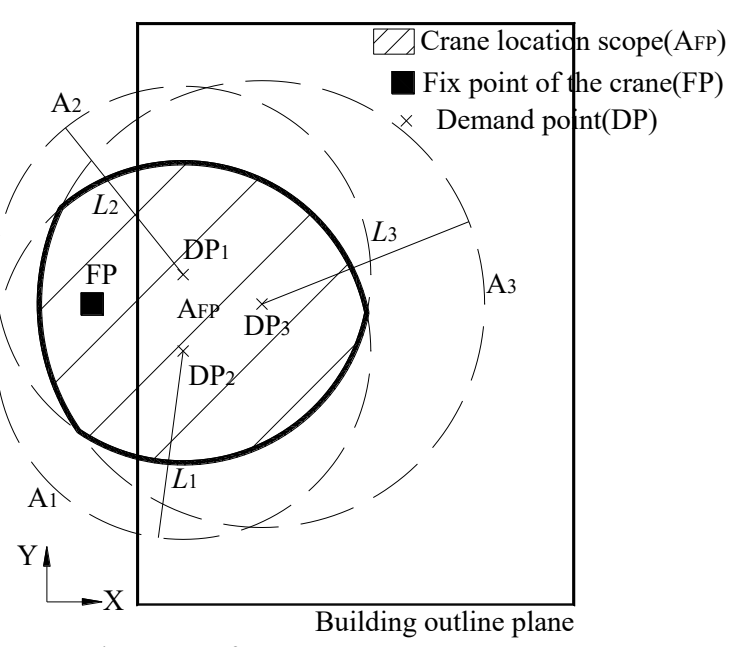

Fig. 4. Location scope of tower crane

The mass of the prefabricated components at $\mathrm{DP}_{1}$ and $\mathrm{DP}_{2}$ is greater than that at $\mathrm{DP}_{3} ; L_{1}, L_{2}$, and $L_{3}$ are the radius of the corresponding prefabricated components that can be lifted by the same tower crane. $\mathrm{A}_{1}, \mathrm{~A}_{2}$, and $\mathrm{A}_{3}$ are the location scope of tower crane corresponding to $\mathrm{DP}_{1}$, $\mathrm{DP}_{2}$, and $\mathrm{DP}_{3}$, which are shown as dotted line circles with $\mathrm{DP}_{1}, \mathrm{DP}_{2}$, and $\mathrm{DP}_{3}$ as the centers, $L_{1}, L_{2}$, and $L_{3}$ as the 
radius. When the tower crane lifts multiple prefabricated components, such components should be located at the shaded area where $A_{1}, A_{2}$, and $A_{3}$ overlap, as shown in Fig. 4. FP is a point in $A_{F P}$, a potential tower crane location. When $n$ installation points for prefabricated components exist, the crane location scope can be calculated through Eq. (2):

$$
\mathrm{A}_{\mathrm{FP}}=\mathrm{A}_{1} \cap \mathrm{A}_{2} \cap \mathrm{A}_{3} \cap \ldots \cap \mathrm{A}_{\mathrm{n}}
$$

where $A_{F P}$ is the location scope of the tower crane; $A_{1}$, $A_{2}$, and $A_{3}$, and $A_{n}$ are the location scope of the tower crane that corresponds to the demand points $\mathrm{DP}_{1}, \mathrm{DP}_{2}, \mathrm{DP}_{3}$, and $\mathrm{DP}_{\mathrm{n}}$.

\subsection{Tower crane cost calculation model}

Reducing construction costs is an important goal in construction and is not only affected by travel time but also by the model of tower cranes. Cost minimization has been considered an important criterion in determining the optimal location of a tower crane, which is taken as a basis for optimizing location decisions. Tower crane $\operatorname{cost} C_{\mathrm{T}}$ is generally divided into fixed and variable costs. Variable cost varies with the use time of the tower crane. Fixed costs include installation and demolition cost $C_{\mathrm{I}}$, and foundation cost $C_{\mathrm{F}}$. Variable cost is rental costs $C_{\mathrm{r}}$ based on daily consumption and lifespan. The objective function is shown in Eq. (3).

$$
C_{\mathrm{T}}=C_{\mathrm{I}}+C_{\mathrm{F}}+T_{\mathrm{t}} \times C_{\mathrm{r}}
$$

where $C_{\mathrm{T}}, C_{\mathrm{I}}$ and $C_{\mathrm{F}}$ represent tower crane, installation and demolition cost and foundation cost, respectively, and the unit is RMB. $C_{\mathrm{r}}$ represents the rental costs of the tower crane and the unit is $\mathrm{RMB} / \mathrm{d}$. $T_{\mathrm{t}}$ is the total time required for lifting in the construction project, and the unit is min.

The location scope of the tower crane is discrete, and the calculation amount is large according to the size of the construction site. To this end, the present study develops an optimization algorithm based on MATLAB platform to accelerate calculation.

\subsection{Tower crane lifting time calculation model}

The lifting process of the tower crane can be divided into vertical and horizontal movements. During the vertical movement, the hook lifts the prefabricated components from SP to SP' at the velocity of $V_{\mathrm{h}}$ (Fig. 5(a)). In the horizontal movement process (Fig. 5(c) and (d)), the crane jib rotates at a certain angle $\theta$ in the horizontal plane, so that the extension part of the jib covers DP. The trolley moves along the jib and slides to the top of the target position DP'. After the component is stabilized, the lifting hook descends to the DP to complete the installation (Fig. 5(b)). Zhang et al. established a calculation model for this process [10].

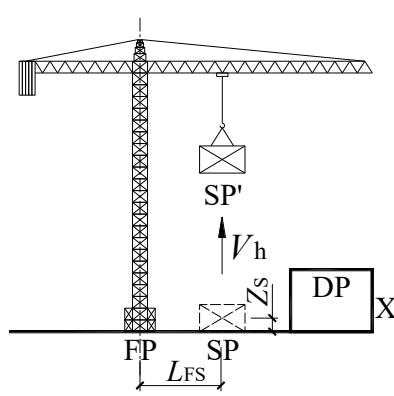

(a)

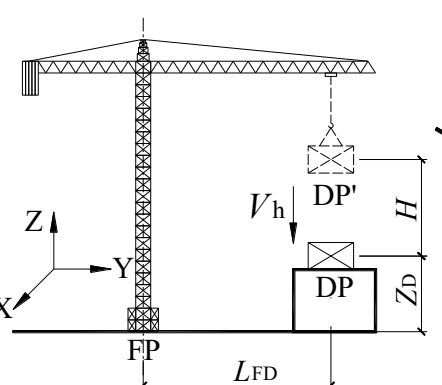

(b)

Fig. 5. Movement of the tower crane

\subsubsection{Calculation of vertical movement time}

The vertical movement of the tower crane can be divided into vertical ascending movement and vertical descending movement. In addition to the difference between the height of the demand point $Z_{\mathrm{D}}$ and the height of the supply point $Z_{\mathrm{S}}$, the lifting height of the transport component should be higher than the height of SP during the actual transportation process to avoid collision between buildings. The vertical movement time $T_{\mathrm{v}}$ of the tower crane is calculated through Eq. (4).

$T_{\mathrm{v}}=\left(\left|Z_{\mathrm{D}}-Z_{\mathrm{s}}\right|+2 H\right) / V_{\mathrm{h}}$

where $T_{\mathrm{v}}$ is the vertical transportation time in a single lifting process, and the unit is $\min ; Z_{\mathrm{D}}$ is the height of the

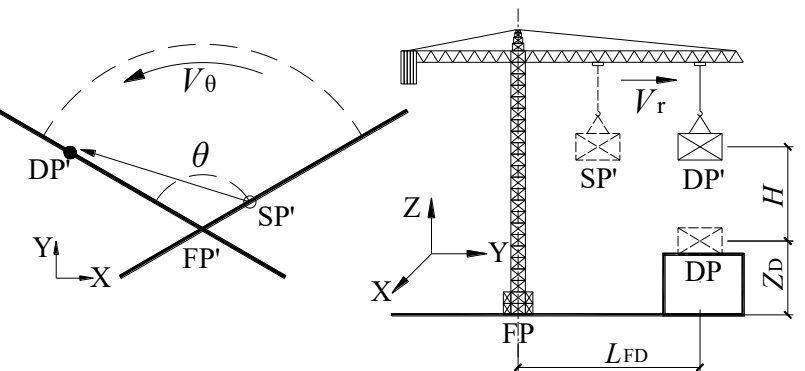

(c)

(d)

demand point, and the unit of $\mathrm{m} ; Z_{\mathrm{S}}$ is the height of the supply point, and the unit is $\mathrm{m} ; H$ is the safety height, and the unit is $\mathrm{m} ; V_{\mathrm{h}}$ is the lifting velocity of the hook, with the unit of $\mathrm{m} / \mathrm{min}$.

\subsubsection{Calculation of horizontal movement timexs}

The horizontal movement of the tower crane can be divided into the rotating movement of the jib and the linear motion of the trolley. Fig. 6 shows the horizontal projection of the location point of the tower crane FP, the demand point DP, and the supply point SP in the $\mathrm{X}-\mathrm{Y}$ axis, the corresponding representation points are $\mathrm{FP}^{\prime}, \mathrm{DP}^{\prime}$, and $\mathrm{SP}^{\prime}$, respectively. When the coordinate is known, the angle $\theta$ in the horizontal projection can be obtained. The main factors that influence the rotating motion include $\theta$ and the rotating angular velocity $V_{\theta}$. Rotating time $T_{\theta}$ and the linear movement time of the trolley $T_{\mathrm{r}}$ can be obtained by Eq. (5) and (6), respectively. 


$$
\begin{aligned}
& T_{\theta}=\frac{\theta}{V_{\theta}},(0 \leq \theta \leq \pi) \\
& T_{\mathrm{r}}=\frac{\left|\rho_{\mathrm{FD}}-\rho_{\mathrm{FS}}\right|}{V_{\mathrm{r}}}
\end{aligned}
$$

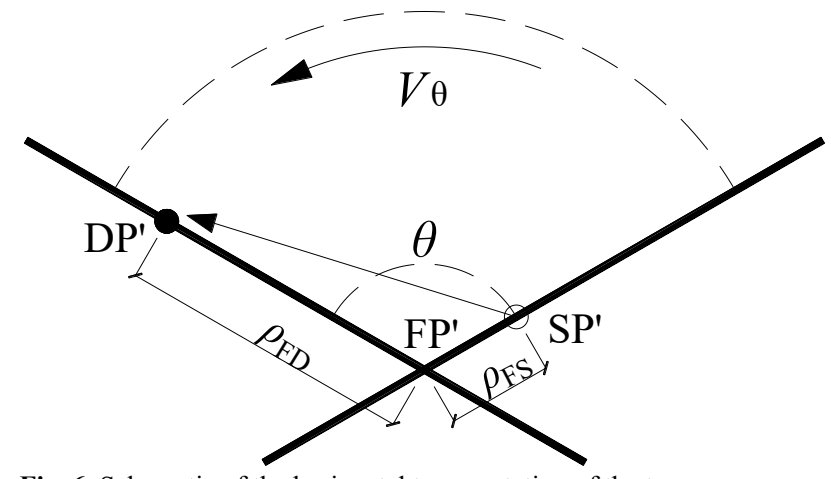

Fig. 6. Schematic of the horizontal transportation of the tower crane

where $T_{\theta}$ is the rotating movement time of the tower crane in a single lifting process, and the unit is min; $T_{\mathrm{r}}$ is the slipping time of the trolley in a single lifting process, and the unit is $\min ; \rho_{\mathrm{FD}}$ is the distance between the horizontal projection $\mathrm{FP}^{\prime}$ of the tower crane and the horizontal projection $\mathrm{DP}^{\prime}$ of the demand point, and the unit is $\mathrm{m} ; \rho_{\mathrm{FS}}$ is the distance between the horizontal projection FP' of the tower crane and the horizontal projection $\mathrm{SP}^{\prime}$ of the supply point, and the unit is $\mathrm{m} ; \theta$ is the included angle with the horizontal projection $\mathrm{FP}^{\prime}$ of the tower crane as the apex, and its connection lines with the horizontal projection SP' of the supply point and the horizontal projection $\mathrm{DP}^{\prime}$ of the demand point as the sides, the unit is rad; $V_{\theta}$ is the rotating velocity of the $\mathrm{jib}$, and the unit is $\mathrm{rad} / \mathrm{min}$; $V_{\mathrm{r}}$ is the slipping velocity of the trolley on the tower crane, with the unit of $\mathrm{m} / \mathrm{min}$.

The rotating of jib and the sliding of trolley can operate simultaneously to improve the efficiency of component transportation. Eq. (7) is employed to calculate the horizontal movement time $T_{\mathrm{h}}$ of the crane in a single lifting process. Parameter $\alpha$ indicates the degree of synchronization between the rotating of the jib and the sliding of the trolley. The value of $\alpha$ is between 0 and 1, respectively indicating complete simultaneous operation and separate operation.

$T_{\mathrm{h}}=\alpha \times T_{\mathrm{r}}+\max \left\{(1-\alpha) T_{\mathrm{r}}, T_{\theta}\right\}$

where $T_{\mathrm{h}}$ is the horizontal movement time of the tower crane in a single lifting process, and the unit is $\min . T_{\theta}$ is the rotating movement time of the tower crane in a single lifting process, and the unit is $\mathrm{min} ; T_{\mathrm{r}}$ is the slipping time of the trolley in a single lifting process, and the unit is min.

\subsubsection{Calculation of lifting movement time}

The tower crane transports the components from SP to DP. During the transportation process, the loading and unloading of the transportation components need to wait for $T_{\mathrm{w}}$, which can be determined on the basis of experience. Therefore, the transportation time of a single component $T_{\mathrm{s}}$ can be calculated by using Eq. (8).

$T_{\mathrm{s}}=T_{\mathrm{v}}+T_{\mathrm{h}}+T_{\mathrm{w}}$

where $T_{\mathrm{s}}$ is the time required for a single lifting process of the tower crane, and the unit min; $T_{\mathrm{v}}$ is the time required for vertical movement in a single lifting process of the tower crane, and the unit is $\min ; T_{\mathrm{h}}$ is the time required for the horizontal movement of the tower crane in a single lifting process, and the unit is $\min ; T_{\mathrm{w}}$ is the waiting time required for a single lifting process of the tower crane, and the unit is $\min$.

In the whole lifting process, the number $I$ of the same type of prefabricated components, the type $J$ of the prefabricated components, and the project layer $K$ determine the total lifting time $T_{\mathrm{t}}$, and the calculation method is as follows:

$T_{\mathrm{t}}=\sum_{k=1}^{K} \sum_{j=1}^{J} \sum_{i=1}^{I} T^{i j k}$

where $T_{\mathrm{t}}$ is the total time required for lifting in the construction project, and the unit is $\min ; K$ is the layer number of the construction project; $J$ is the type of the prefabricated components; $I$ is the number of the same type of prefabricated components.

\section{Result Analysis and Discussion}

In this study, the prefabrication ratio $P$ of a single building is defined as the proportion of the total mass of prefabricated components in the concrete structure of a building and can be calculated through Eq. (10).

$$
P=\frac{Q_{\mathrm{P}}}{Q_{\mathrm{I}}+Q_{\mathrm{P}}} \times 100 \%
$$

where $P$ is the prefabrication ratio of a single building; $Q_{\mathrm{P}}$ is the total mass of prefabricated components, and the unit is $\mathrm{t}$; $Q_{\mathrm{I}}$ is the mass of the cast-in-place part of the main structure, and the unit is $t$.

The optimal selection and location of the tower crane are determined with a ten-story male apartment in Chongqing as an example, based on the model proposed in Chapter 3. Moreover, the optimal combination of prefabricated components under different prefabrication ratios is analyzed. The male apartment covers an area of $43.8 \times 17.6 \mathrm{~m}$. 


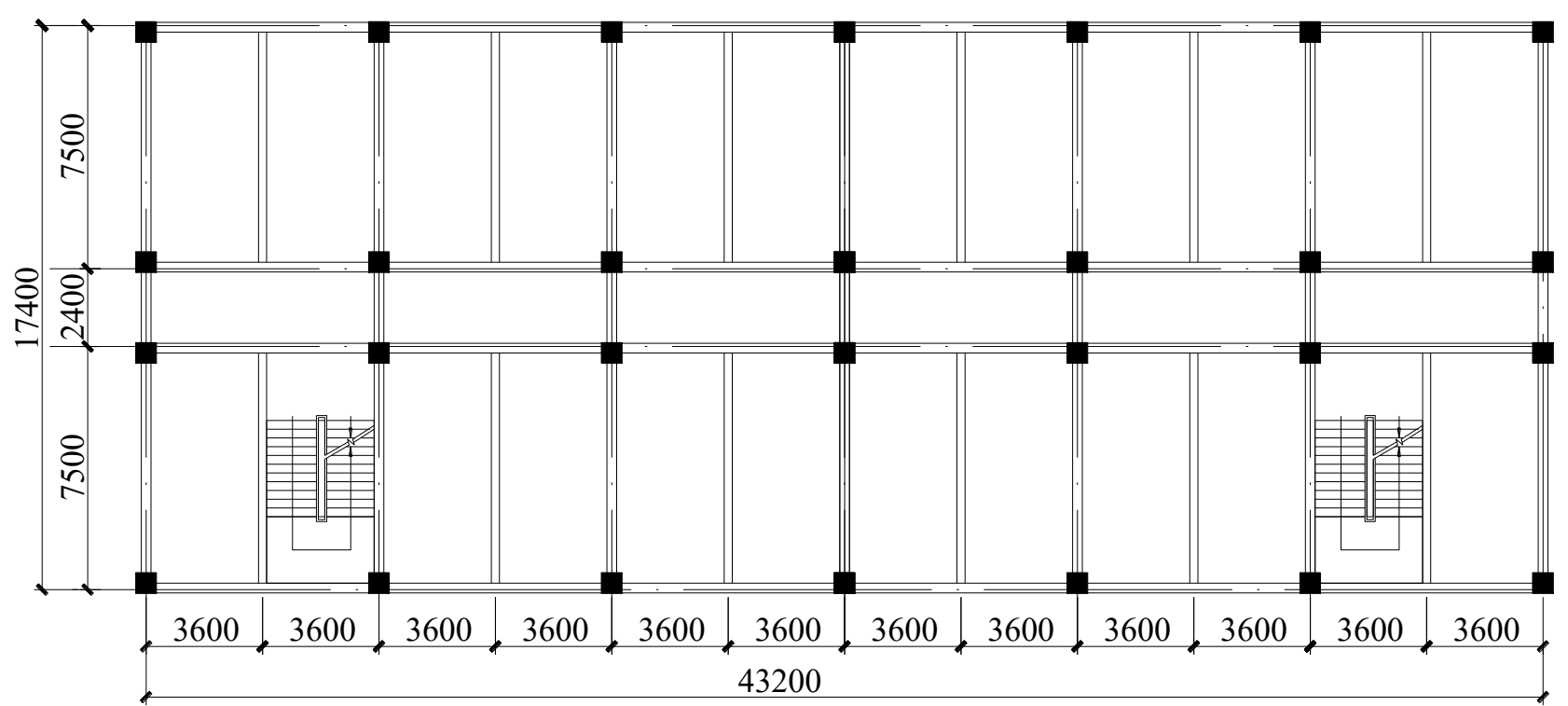

Note: The unit of this figure is $\mathrm{mm}$.

Fig. 7. Schematic of a male apartment building

An attached tower crane is used, and the layout of the construction site is shown in Fig. 7. According to practical experience, the distance between the building boundary and the tower crane is assumed to be $2 \mathrm{~m}$, the crane can be arranged in a range of $1 \mathrm{~m}$ and $\alpha$ take 0.5 .The project has four types of prefabricated components, including prefabricated column, beam, floor, and stair. Based on the tower crane preliminary selection model in Section 3.1, C6018, C5513, and C5013 attached tower cranes are selected.

Table 1 shows the cost components of the attached tower crane, including installation and disassembly cost $C_{\mathrm{I}}$, foundation cost $C_{\mathrm{F}}$ and rental costs $C_{\mathrm{r}}$. According to the Eq. (2) - (4), the optimal selection and location of the tower crane with the minimum cost are determined on the MATLAB platform. Table 2 gives the performance parameters in the calculation of the tower crane lifting time.

Table 1. Cost components of the attached tower cranes

\begin{tabular}{l|c|c|c}
\hline \multirow{2}{*}{ Cost } & \multicolumn{3}{|c}{ Types of attached tower crane } \\
\cline { 2 - 4 } & C5013 & C5513 & C6018 \\
\hline$C_{\mathrm{I}}(\mathrm{RMB})$ & 39,800 & 46,200 & 74,800 \\
$C_{\mathrm{F}}(\mathrm{RMB})$ & 20,250 & $24,502.5$ & 29,160 \\
$C_{\mathrm{r}}(\mathrm{RMB} / \mathrm{d})$ & 600 & 700 & 1,200 \\
\hline
\end{tabular}

Table. 2. Performance parameters of lifting of the attached tower cranes

\begin{tabular}{l|c|c|c}
\hline \multirow{2}{*}{ Parameters } & \multicolumn{3}{|c}{ Types of attached tower crane } \\
\cline { 2 - 4 } & $\mathbf{C 5 0 1 3}$ & $\mathbf{C 5 5 1 3}$ & $\mathbf{C 6 0 1 8}$ \\
\hline$L_{\max }(\mathrm{m})$ & 50 & 55 & 60 \\
$Q_{L \max }(\mathrm{t})$ & 1.3 & 1.3 & 1.8 \\
$V_{\mathrm{h}}(\mathrm{m} / \mathrm{min})$ & 41.6 & 43.3 & 51.4 \\
$V_{\theta}(\mathrm{rad} / \mathrm{min})$ & 0.7 & 0.7 & 0.7 \\
$V_{\mathrm{r}}(\mathrm{m} / \mathrm{min})$ & 40 & 58 & 58 \\
$H(\mathrm{~m})$ & 3 & 3 & 3 \\
\hline
\end{tabular}

Each project has a personalized optimization layout plan because of the different constraints on the construction site. Exploring the main influencing factors and time variation law in different situations can help determine the optimal layout plan. In fact, considering the layout of other facilities (e.g., steel cutters), SP is often fixed in one position. In the actual construction layout, SP is mostly located at the center and corner points of each side in a construction project.

Therefore, the optimal combination of prefabricated components and the optimal selection and location of the tower crane under different prefabrication ratios in the three following cases are discussed.

\subsection{Case 1: SP is located at the midpoint of the long side of the project}

C5013, C5513 and C6018 are arranged in an area that overlaps with the attachment path based on the range obtained in Section 3.2. Table 3 shows different combinations of prefabricated components based on the calculation formulas in Sections 3.3 and 3.4. When prefabricated stair is the only prefabricated component, C5013 is the optimal choice, with the lowest cost of 60051.56 RMB. In fact, most contractors use fewer prefabricated components to meet the requirements for the prefabrication ratio because prefabricated components are expensive. When the required prefabrication ratio is not less than $30 \%$, the cost of using prefabricated beam is the lowest, and C5513 is the optimal crane type. When the required prefabrication ratio is not less than $50 \%$, the combination of using prefabricated column and beam is the best selection, and C5513 is also the optimal crane type.

Due to the prefabrication ratio of $50 \%$ is the requirement of most construction projects, the combination of prefabricated beam and column is selected to find the relationship between the location of tower crane and lifting time to make a reference for the location of the tower crane on site. Based on the tower crane location scope calculation model in Section 3.2, C5513 can only be located on the long side of the project. However, by using C6018, a larger range of location is obtained to better find the relationship. Therefore, C6018 is selected to reveal the law. When FP and SP are on the same side, the lifting time is longer than they located on the opposite side as shown in Fig. 8. Moreover, when SP and FP are at the same side, the lifting time shrinks with $L_{\mathrm{FS}}$. 
Table. 3. Total lifting time and cost of attached tower cranes when the supply point is located at the midpoint of the long side

\begin{tabular}{|c|c|c|c|c|c|c|c|c|}
\hline \multirow{2}{*}{$\begin{array}{c}\text { Serial } \\
\text { number }\end{array}$} & \multirow{2}{*}{$\begin{array}{c}\text { Prefabricated } \\
\text { components }\end{array}$} & \multirow{2}{*}{$\boldsymbol{P}$} & \multicolumn{3}{|c|}{$T_{\mathrm{t}}$ (min) } & \multicolumn{3}{|c|}{$C_{\mathrm{T}}(\mathbf{R M B})$} \\
\hline & & & C5013 & C5513 & C6018 & C5013 & C5513 & C6018 \\
\hline 1 & $\mathrm{~S}$ & $1 \%$ & 1.25 & 1.24 & 2.88 & 60051.56 & 70704.30 & 103963.02 \\
\hline 2 & $\mathrm{C}$ & $18 \%$ & NA & 17.62 & 17.13 & NA & NA & 104002.83 \\
\hline 3 & $\mathrm{C}+\mathrm{S}$ & $19 \%$ & NA & 18.86 & 18.35 & NA & NA & 104005.88 \\
\hline 4 & $\mathrm{~F}$ & $23 \%$ & NA & NA & 18.46 & NA & NA & 104006.15 \\
\hline 5 & $\mathrm{~F}+\mathrm{S}$ & $24 \%$ & NA & NA & 19.68 & NA & NA & 104009.20 \\
\hline 6 & B & $33 \%$ & NA & 34.85 & 33.79 & NA & 70753.33 & 104044.48 \\
\hline 7 & $\mathrm{~B}+\mathrm{S}$ & $34 \%$ & NA & 36.09 & 35.01 & NA & 70755.13 & 104047.53 \\
\hline 8 & $\mathrm{C}+\mathrm{F}$ & $41 \%$ & NA & NA & 35.66 & NA & NA & 104049.14 \\
\hline 9 & $\mathrm{C}+\mathrm{F}+\mathrm{S}$ & $42 \%$ & NA & NA & 36.87 & NA & NA & 104052.18 \\
\hline 10 & $\mathrm{C}+\mathrm{B}$ & $51 \%$ & NA & 52.48 & 50.93 & NA & 70779.03 & 104087.33 \\
\hline 11 & $\mathrm{C}+\mathrm{B}+\mathrm{S}$ & $52 \%$ & NA & 53.71 & 52.15 & NA & 70780.83 & 104090.37 \\
\hline 12 & $\mathrm{~B}+\mathrm{F}$ & $56 \%$ & NA & NA & 52.34 & NA & NA & 104090.85 \\
\hline 13 & $\mathrm{~F}+\mathrm{S}+\mathrm{B}$ & $57 \%$ & NA & NA & 53.56 & NA & NA & 104093.90 \\
\hline 14 & $\mathrm{C}+\mathrm{B}+\mathrm{F}$ & $74 \%$ & NA & NA & 69.53 & NA & NA & 104133.83 \\
\hline 15 & $\mathrm{C}+\mathrm{B}+\mathrm{F}+\mathrm{S}$ & $75 \%$ & NA & NA & 70.75 & NA & NA & 104136.88 \\
\hline
\end{tabular}

Note: $\mathrm{S}$ represents stair, $\mathrm{C}$ represents column, $\mathrm{F}$ represents floor, B represents beam and NA refers to not available.

Table. 4. Total lifting time and cost of the attached tower crane when the supply point is located at the midpoint of the short side

\begin{tabular}{|c|c|c|c|c|c|c|c|c|}
\hline \multirow{2}{*}{$\begin{array}{c}\text { Serial } \\
\text { number }\end{array}$} & \multirow{2}{*}{$\begin{array}{l}\text { Prefabricated } \\
\text { components }\end{array}$} & \multirow{2}{*}{$P$} & \multicolumn{3}{|c|}{$T_{\mathrm{t}}(\mathbf{m i n})$} & \multicolumn{3}{|c|}{$C_{\mathrm{T}}(\mathbf{R M B})$} \\
\hline & & & C5013 & C5513 & C6018 & C5013 & C5513 & C6018 \\
\hline 1 & $\mathrm{~S}$ & $1 \%$ & 2.94 & 2.92 & 2.85 & 60051.60 & 70704.35 & 103963.10 \\
\hline 2 & $\mathrm{C}$ & $18 \%$ & NA & 41.63 & 40.74 & NA & 70728.90 & 104004.28 \\
\hline 3 & $\mathrm{C}+\mathrm{S}$ & $19 \%$ & NA & 44.56 & 43.60 & NA & 70730.76 & 104007.39 \\
\hline 4 & $\mathrm{~F}$ & $23 \%$ & NA & NA & 44.00 & NA & NA & 104007.83 \\
\hline 5 & $\mathrm{~F}+\mathrm{S}$ & $24 \%$ & NA & NA & 46.87 & NA & NA & 104010.95 \\
\hline 6 & B & $33 \%$ & NA & 82.47 & 80.54 & NA & 70754.79 & 104047.55 \\
\hline 7 & $\mathrm{~B}+\mathrm{S}$ & $34 \%$ & NA & 85.45 & 83.42 & NA & 70756.68 & 104050.68 \\
\hline 8 & $\mathrm{C}+\mathrm{F}$ & $41 \%$ & NA & NA & 84.75 & NA & NA & 104052.12 \\
\hline 9 & $\mathrm{C}+\mathrm{F}+\mathrm{S}$ & $42 \%$ & NA & NA & 87.62 & NA & NA & 104055.24 \\
\hline 10 & $\mathrm{C}+\mathrm{B}$ & $51 \%$ & NA & 124.11 & 121.28 & NA & 70781.19 & 104091.83 \\
\hline 11 & $\mathrm{C}+\mathrm{B}+\mathrm{S}$ & $52 \%$ & NA & 127.08 & 124.17 & NA & 70783.08 & 104094.97 \\
\hline 12 & $\mathrm{~B}+\mathrm{F}$ & $56 \%$ & NA & NA & 124.55 & NA & NA & 104095.38 \\
\hline 13 & $\mathrm{~F}+\mathrm{S}+\mathrm{B}$ & $57 \%$ & NA & NA & 127.44 & NA & NA & 104098.52 \\
\hline 14 & $\mathrm{C}+\mathrm{B}+\mathrm{F}$ & $74 \%$ & NA & NA & 165.29 & NA & NA & 104139.67 \\
\hline 15 & $\mathrm{C}+\mathrm{B}+\mathrm{F}+\mathrm{S}$ & $75 \%$ & NA & NA & 168.18 & NA & NA & 104142.81 \\
\hline
\end{tabular}

Note: $\mathrm{S}$ represents stair, $\mathrm{C}$ represents column, F represents floor, B represents beam and NA refers to not available.

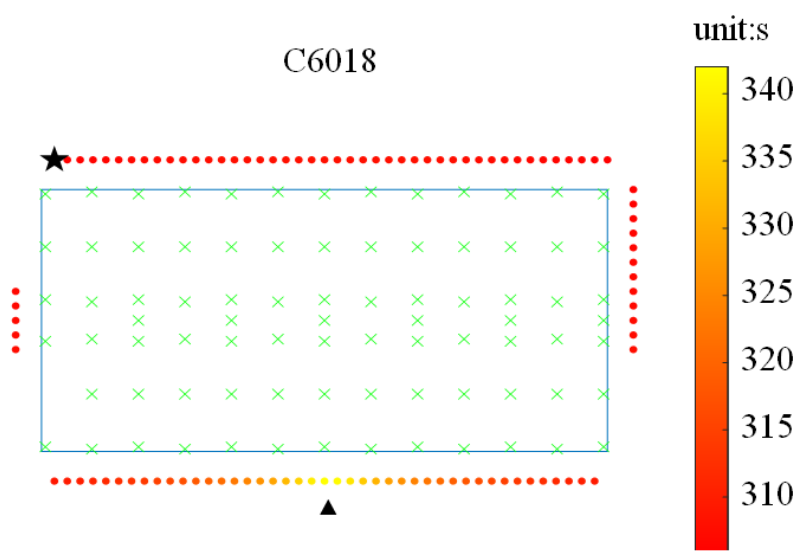

$\times$ Demand point of prefabricated beams and columns

$\star$ Optimal location of tower crane $\Delta$ Supply point

- Location scope of tower crane

Note: The colour code on the right side is the time required for lifting all prefabricated components. The redder the colour, the shorter the time required for lifting at this point.

Fig. 8. Lifting time of C6018 lifting prefabricated column and prefabricated beam when the supply point is located at the midpoint of the long side

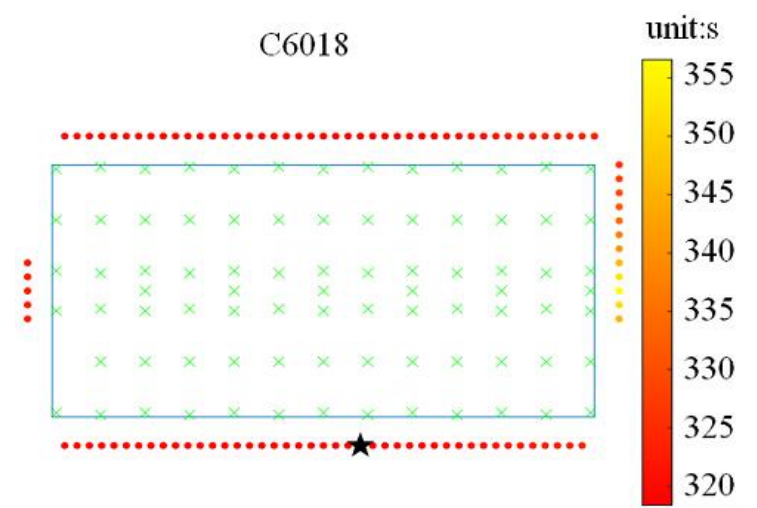

$\times$ Demand point of prefabricated beams and columns

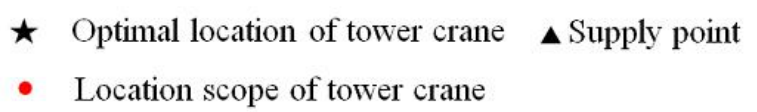

Note: The colour code on the right side is the time required for lifting all prefabricated components. The redder the colour, the shorter the time required for lifting at this point.

Fig. 9. Lifting time of C6018 lifting prefabricated column and prefabricated beam when the supply point is located at the midpoint of the short side 


\subsection{Case 2: SP is located at the midpoint of the short side of the project}

When SP is located at the midpoint of the short side of the project, the results are calculated by running the calculation on the MATLAB platform based on the model proposed in Sections 3.2-3.4 as shown in Table 4. When the prefabricate component is stair, the lowest cost of the tower crane can be achieved, which is 60,898.49 RMB, slightly higher than the optimal cost when the supply point is located at the midpoint of the long side, but the prefabrication ratio is the lowest, only 0.01 . When the required prefabrication ratio is $30 \%$ and above, the optimal prefabricated component choice is prefabricated beam, with a prefabrication ratio of $33 \%$ and a tower crane cost of 70754.79 RMB. When the required prefabrication ratio is $50 \%$ and above, the optimal prefabricated component combination is prefabricated beam and column, with a prefabrication ratio of $51 \%$ and a tower crane cost of 70781.19 RMB.

For the same reason as case 1, this part chooses the combination of prefabricated beam and column and selects C6018. When SP is at the midpoint of the short side, C6018 is not able to locate at short side. And among C6018's location scope of the long sides, when the tower crane is on both sides, the hoisting time is longer than it nearby the middle (Fig. 9).

\subsection{Case 3: SP is located at the angular point of the project}

When the supply point is located at the angular point of the construction project, based on the model in Sections 3.2-3.4, the results of calculation are obtained by running the MATLAB platform (Table 5). Similar to the cases in Sections 4.2 and 4.3, when stair is the only prefabricated component, the cost of the tower crane is the lowest, 60051.60 RMB. This value is the same as that in Section 4.3, which is slightly higher than the optimal cost when the supply point is at the midpoint of the long side.

However, the prefabrication ratio is 0.01 . When the required prefabrication ratio is $30 \%$ and above, the optimal prefabricated component combination is prefabricated beam, the prefabrication ratio is $33 \%$, and the tower crane cost is $70755.40 \mathrm{RMB}$. When the prefabrication ratio is $50 \%$ and above, the optimal prefabricated component combination is prefabricated beam and column, with a prefabrication ratio of $51 \%$ and a tower crane cost of $70782.06 \mathrm{RMB}$, which is higher than the tower crane cost in Section 4.1 and 4.2.

Table 5. Total lifting time and cost of the attached tower crane when the supply point is located at the angular point

\begin{tabular}{|c|c|c|c|c|c|c|c|c|}
\hline \multirow{2}{*}{$\begin{array}{c}\text { Serial } \\
\text { number }\end{array}$} & \multirow{2}{*}{$\begin{array}{l}\text { Prefabricated } \\
\text { components }\end{array}$} & \multirow{2}{*}{$\boldsymbol{P}$} & \multicolumn{3}{|c|}{$T_{\mathrm{t}}$ (min) } & \multicolumn{3}{|c|}{$C_{\mathrm{T}}$ (RMB) } \\
\hline & & & C5013 & C5513 & C6018 & C5013 & C5513 & C6018 \\
\hline 1 & $\mathrm{~S}$ & $1 \%$ & 2.94 & 2.92 & 2.85 & 60051.60 & 70704.35 & 103963.10 \\
\hline 2 & $\mathrm{C}$ & $18 \%$ & NA & 42.04 & 40.55 & NA & 70729.16 & 104004.08 \\
\hline 3 & $\mathrm{C}+\mathrm{S}$ & $19 \%$ & NA & 45.00 & 43.42 & NA & 70731.03 & 104007.20 \\
\hline 4 & $\mathrm{~F}$ & $23 \%$ & NA & NA & 43.83 & NA & NA & 104007.65 \\
\hline 5 & $\mathrm{~F}+\mathrm{S}$ & $24 \%$ & NA & NA & 46.69 & NA & NA & 104010.75 \\
\hline 6 & $\mathrm{~B}$ & $33 \%$ & NA & 83.43 & 80.01 & NA & 70755.40 & 104046.97 \\
\hline 7 & $\mathrm{~B}+\mathrm{S}$ & $34 \%$ & NA & 86.38 & 82.88 & NA & 70757.27 & 104050.09 \\
\hline 8 & $\mathrm{C}+\mathrm{F}$ & $41 \%$ & NA & NA & 84.75 & NA & NA & 104052.12 \\
\hline 9 & $\mathrm{C}+\mathrm{F}+\mathrm{S}$ & $42 \%$ & NA & NA & 87.34 & NA & NA & 104054.94 \\
\hline 10 & $\mathrm{C}+\mathrm{B}$ & $51 \%$ & NA & 125.48 & 120.57 & NA & 70782.06 & 104091.05 \\
\hline 11 & $\mathrm{C}+\mathrm{B}+\mathrm{S}$ & $52 \%$ & NA & 128.43 & 123.43 & NA & 70783.93 & 104094.17 \\
\hline 12 & $\mathrm{~B}+\mathrm{F}$ & $56 \%$ & NA & NA & 124.17 & NA & NA & 104094.96 \\
\hline 13 & $\mathrm{~F}+\mathrm{S}+\mathrm{B}$ & $57 \%$ & NA & NA & 127.02 & NA & NA & 104098.07 \\
\hline 14 & $\mathrm{C}+\mathrm{B}+\mathrm{F}$ & $74 \%$ & NA & NA & 164.82 & NA & NA & 104139.15 \\
\hline 15 & $\mathrm{C}+\mathrm{B}+\mathrm{F}+\mathrm{S}$ & $75 \%$ & NA & NA & 167.68 & NA & NA & 104142.26 \\
\hline
\end{tabular}

Note: $\mathrm{S}$ represents stair, C represents column, F represents floor, B represents beam and NA refers to not available.

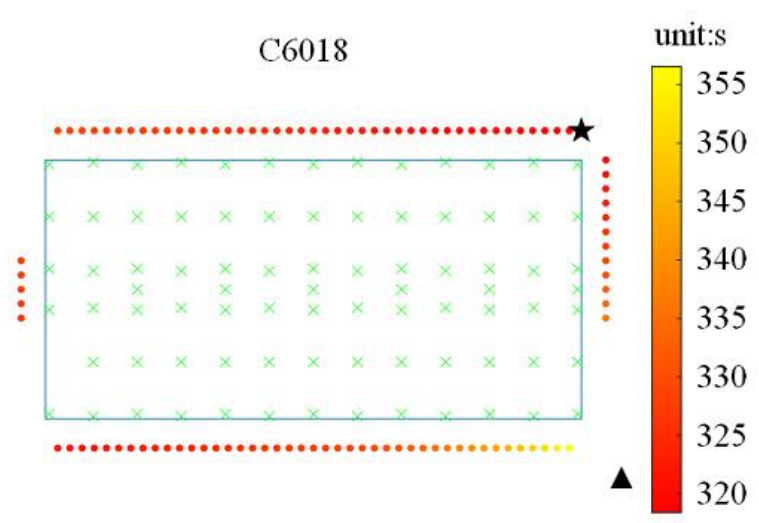

$\times$ Demand point of prefabricated beams and columns

$\star$ Optimal location of tower crane $\Delta$ Supply point

- Location scope of tower crane

Note: The colour code on the right side is the time required for lifting all prefabricated components. The redder the colour, the shorter the time required for lifting at this point.
Fig. 10. Lifting time of C6018 lifting prefabricated column and prefabricated beam when the supply point is located at the angular point

As the same reason as case 1, this part chose the combination of prefabricated beam and column using C6018. That is, the optimal location law of the tower crane is explored in the combination of prefabricated beam and column. When SP is at the angular point and tower crane is located at near long side and short side, the lifting time is shorter when the $L_{\mathrm{FS}}$ is larger (Fig. 10). When the tower crane is located on the long opposite side, the lifting time is shortened as $L_{\mathrm{FS}}$ decreases.

\section{Conclusions}

A novel optimization model based on the relationship among the tower crane, the demand and supply point, combined lifting process, and aimed at realize minimal cost was developed to estimate the optimal selection and location of tower crane. The objective is to evaluate the optimal combination of prefabricated components under different 
prefabrication ratios and reveal the optimal selection and location of the tower crane. A case study was analyzed to reveal the relationship of prefabricated ratio, prefabricated component combinations, and tower crane optimal selection and location. The following conclusions could be drawn:

(1) The proposed tower crane selection and location model are more cost-effective than the traditional experience-based methods.

(2) When the required prefabrication ratio is not less than $30 \%$, selecting prefabricated beams as the prefabricated components is the most economic; when the required prefabrication ratio is not less than $50 \%$, selecting prefabricated column and beam as the prefabricated components is the most economic.

(3) Compared with the cases in which SP is at the midpoint of the short side and the angular point, when SP is at the midpoint of the long side, the cost of the tower crane is the lowest, and the optimal location of the tower crane is angular point of the long side opposite SP.

Thus, the lifting time of tower crane is considered in the proposed method to evaluate the cost of the tower crane accurately. However, the cost of tower crane is influenced by many factors, and the proposed optimization model lacks actual project information, such as prefabricated component loading and unloading time. More field observations that provide accurate loading and unloading time should be considered in future studies.

\section{Acknowledgements}

This work was supported by the Fundamental Research Funds for Central Universities (Project No. 2019CDSKXYJSG0041), the Youth Project of Science and Technology Research Program of Chongqing Education Commission of China (Project No. KJQN201800125), the City Science of Chongqing (Integration and demonstration of key technology research of prefabricated housing construction, 2015 No. 0-1), and Chongqing Graduate Research and Innovation Foundation (Grant No. CYS19016).

This is an Open Access article distributed under the terms of the Creative Commons Attribution License

\section{References}

1. Green, D., "Buy or rent?". Journal of the American College of Radiology, 12(5), 2015, pp.512-512.

2. Dasović, B., Galić, M., Klanšek, U., "Active BIM Approach to Optimize Work Facilities and Tower Crane Locations on Construction Sites with Repetitive Operations". Buildings, 9(1), 2019, pp.9-21.

3. Sun, Y., Sun, S., Li C., Yang, Y., Ma, T., Yan, M., "Research on construction technology of tower crane in precast concrete structure”. building technology, 48 (8), 2017, pp. 809-811. (in Chinese)

4. Li, D., Wang, Y., "Driving and obstacle factors affecting construction unit's initiative adoption of prefabricated buildings". Journal of civil engineering and management, 36 (03), 2019, pp. 711. (in Chinese)

5. Nadoushani, Z. S. M., Hammad, A. W. A., \& Akbarnezhad, A., "Location optimization of tower crane and allocation of material supply points in a construction site considering operating and rental". Journal of Construction Engineering \& Management, 143(1), 2016, 04016089.

6. Fu, Y., Li, R., Liu, G., Xu, P., Mao, C., "Technical and economic analysis of tower crane based on value engineering theory". Journal of engineering management, 33 (04), 2019, pp. 117- 121. (in Chinese)

7. Marzouk, M., Abubakr, A., "Decision support for tower crane selection with building information models and genetic algorithms". Automation in Construction, 61,2016, pp. 1-15.

8. Zhang, P., Harris, F. C., Olomolaiye, P. O., "A computer - based model for optimizing the location of a single tower crane". Building Research \& Information, 24(2), 2, 1996, pp. 113-123.

9. Zhang, P., Harris, F. C., Olomolaiye, P. O., Holt, G. D., "Location optimization for a group of tower cranes". Journal of Construction Engineering \& Management, 125(2), 1999, pp. 115-122.
10. Briskorn, D., Dienstknecht, M., "Mixed-integer programming models for tower crane selection and positioning with respect to mutual interference". European Journal of Operational Research, 273(1), 2019, pp. 160-174.

11. Lien, L. C., Cheng, M. Y., "Particle bee algorithm for tower crane layout with material quantity supply and demand optimization". Automation in Construction, 45(45), 2014, pp. 25-32.

12. Yeoh, J. K. W., Chua, D. K. H., "Optimizing crane selection and location for multistage construction using a four-dimensional set cover approach". Journal of Construction Engineering \& Management, 143(8), 2017, pp. 04017029.

13. Zhu, F., "Study on safety control of combined tower crane foundation". Construction technology, 44 (05), 2015, pp.19-21. (in Chinese)

14. Song, Y., "Selection of tower crane for installation and construction of prefabricated concrete structure". Architectural technology, 49 (S1), 2018, pp. 41-43. (in Chinese)

15. C. M. Tam, Thomas K. L. Tong., "Ga-ann model for optimizing the locations of tower crane and supply points for high-rise public housing construction". Construction Management \&Economics, 21(3), 2003, pp. 257-266.

16. Kaveh, A., Yasin, V., "Optimization of tower crane location and material quantity between supply and demand points: a comparative study". Periodica Polytechnica Civil Engineering, 62(3), 2018, pp. $732-745$.

17. Irizarry, J., Karan, E. P., "Optimizing location of tower cranes on construction sites through gis and bim integration". Electronic Journal of Information Technology in Construction, 17(1110), 2012, pp. 351-366.

18. Xiang, H., Wu, Y., Ma, Q., Zhang, H., Han, L., "Spatial positioning and selection of tower crane based on BIM Technology". Construction technology, 46 (S2), 2017, pp. 1236-1239. (in Chinese)

19. Pan, W., Zhao, B., "A group of construction scheme of dynamic simulation and analysis using BIM5D technology". Construction technology, 46 (S2), 2017, pp. 1209-1212. (in Chinese) 